\title{
Conducting composite materials from the biopolymer kappa-carrageenan and carbon nanotubes
}

\author{
Ali Aldalbahi ${ }^{1} \S$, Jin $\mathrm{Chu}^{2}$, Peter Feng ${ }^{2}$ and Marc in het Panhuis ${ }^{* 1}$
}

\section{Full Research Paper}

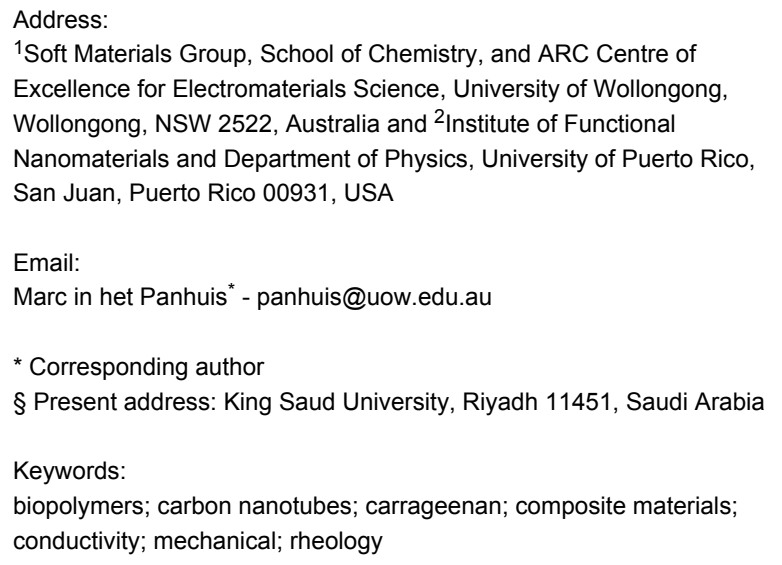

${ }^{1}$ Soft Materials Group, School of Chemistry, and ARC Centre of Excellence for Electromaterials Science, University of Wollongong, Wollongong, NSW 2522, Australia and ${ }^{2}$ Institute of Functional Nanomaterials and Department of Physics, University of Puerto Rico, San Juan, Puerto Rico 00931, USA

Email:

Marc in het Panhuis ${ }^{*}$ - panhuis@uow.edu.au

* Corresponding author

§ Present address: King Saud University, Riyadh 11451, Saudi Arabia

Keywords:

biopolymers; carbon nanotubes; carrageenan; composite materials;

conductivity; mechanical; rheology

Beilstein J. Nanotechnol. 2012, 3, 415-427.

doi:10.3762/bjnano.3.48

Received: 14 March 2012

Accepted: 26 April 2012

Published: 23 May 2012

This article is part of the Thematic Series "Nanostructures for sensors, electronics, energy and environment".

Guest Editor: N. Motta

(C) 2012 Aldalbahi et al; licensee Beilstein-Institut.

License and terms: see end of document.

\begin{abstract}
Conducting composite films containing carbon nanotubes (CNTs) were prepared by using the biopolymer kappa-carrageenan (KC) as a dispersant. Rheological studies indicated that $0.5 \% \mathrm{w} / \mathrm{v}$ was the appropriate $\mathrm{KC}$ concentration for dispersing CNTs. Our results showed that multiwalled nanotubes (MWNTs) required less sonic energy than single-walled nanotubes (SWNTs) for the dispersion process to be complete. Films prepared by vacuum filtration exhibited higher conductivity and improved mechanical characteristics compared to those prepared by evaporative casting. All composite films displayed sensitivity to water vapour, but MWNT films were more sensitive than SWNT films.
\end{abstract}

\section{Introduction}

Carbon nanotubes (CNTs) have attracted attention due to their unique electronic, mechanical, optical and thermal properties, which make them suitable for applications in nanotechnology [1-4]. However, one of the main disadvantages of CNTs is their process-ability; they are difficult to disperse in most common solvents due to their high surface energy and van der Waals interactions [3,5-7]. To overcome this issue, a diverse range of molecules have been used to aid the dispersion of CNTs in aqueous media, such as surfactants, polymers and biopolymers [8-16]. Well known examples of surfactants and polymers include, sodium dodecyl sulfonate, Triton X-100 and polystyrene sulfonate [17-24]. In addition, it has been established that biopolymers such as gellan gum, xanthan gum, gum arabic and iota-carrageenan are effective for the dispersion of CNTs in aqueous solutions [8,25-29]. For example, gellan gum-CNT dispersions have been wet-processed by inkjet printing into 
optically transparent films, which displayed sensitivity to water vapour [30].

Other commonly employed wet-processing methods used to process biopolymer-CNT dispersions into materials include (but are not limited to) evaporative casting, vacuum filtration and fibre spinning $[11,29]$. Formation of films by evaporation is well-known and involves the controlled evaporation of the solvent from a CNT dispersion. It has been established that the mechanical and electrical characteristics of these CNT networks are contingent on the $\mathrm{CNT} /$ dispersant ratio. Increasing the nanotube concentration usually leads to an increase in the electrical conductivity and to mechanical reinforcement [31,32]. Vacuum filtration of dispersions usually results in films, which are generally referred to as buckypapers $[9,33]$. These films can be defined as an entangled network of CNTs, which are held together by van der Waals interactions at the CNT-CNT junctions and are arranged in a two-dimensional structure [34]. Although the formation of buckypapers is straightforward, it has been shown that the electrical, mechanical and physical characteristics are dependent on various parameters, such as the type of CNTs (SWNT or MWNT), the filtration substrate (pore size; hydrophilic or hydrophobic), the sonication time and the type of dispersant (surfactants or polymers) [9,33]. The electrical properties combined with their flexible nature makes CNT networks ideal for a number of potential applications, such as solar cells, displays, touch screens, sensors, electronic paper, supercapacitors and batteries [35-38].

Carrageenans are a biopolymer family of water-soluble, linear, sulfonated galactans extracted from various sources of the Rhodophyta (marine red algae). The carrageenans are well known for their gel-forming and thickening properties $[39,40]$. This biopolymer is an anionic polysaccharide whose structure contains galactose, 3,6-anhydrogalactose units, carboxy and hydroxy groups and ester sulfates. There are three types of carrageenan depending on the number of charged sulfated groups per biopolymer repeat unit, i.e., kappa-carrageenan (one group), iota-carrageenan (two groups) and lambda-carrageenan (three groups) [39]. Carrageenans have been extensively employed in the food industry and are commonly referred to as E407 (European Union specification) as well as being approved by the US Food and Drug Administration as a direct food additive [40]. Recent demonstrations of other applications include their use in drug delivery for the inhibition of viral infections $[41,42]$.

Glycerin (or glycerol, glycerine) is a polyol compound widely used in a diverse range of industries. For example, in the food industries it is added as a humectant, while it is also used to produce an essential ingredient (glyceryl nitrate) for explosives.
Of particular relevance to the research presented in this paper is its usage as a plasticizer to increase the flexibility of polymer films [43].

In this work, it is shown that kappa-carrageenan $(\mathrm{KC})$ is a suitable dispersant for the stabilization of SWNTs and MWNTs in water. The KC concentration and sonication time were optimised to facilitate the efficient dispersion of these CNTs. The electrical and mechanical characteristics of free-standing composite films prepared by evaporative casting and vacuum filtration were assessed, including the effect of incorporating the plasticizer glycerin. The gas-sensing ability of these composite films is demonstrated.

\section{Results and Discussion \\ Rheological of carrageenan solutions}

Rheology is a suitable method for following any changes in viscosity of gel-forming polymers, such as the carrageenans. This is an important step due to the adverse effect that the viscosity of a solution can have on the sonication process. Polymers undergo a dilute to semidilute transition resulting in a significant change in their viscosity. High viscosity is undesirable as it decreases CNT mobility, which impedes the efficiency of the dispersion process. Therefore, our initial studies focussed on establishing the appropriate biopolymer concentration using flow-curve analysis. The viscosity was measured as a function of shear rate for $\mathrm{KC}$ solutions over a concentration range of $0.2-1.2 \% \mathrm{w} / \mathrm{v}$ at $21{ }^{\circ} \mathrm{C}$ (Figure 1a). All $\mathrm{KC}$ solutions displayed shear-thinning behaviour, i.e., decreasing viscosity $(\eta)$ with increasing shear rate $(\dot{\gamma})$. These flow curves were fitted to the well-known power-law model [44]:

$$
\eta=K \dot{\gamma}^{n-1}
$$

where $K$ and $n$ indicate the "consistency" and power-law index, respectively. Figure 1a shows that the viscosity of KC solutions increased with increasing concentration. For example, the apparent viscosity of the $\mathrm{KC}$ solution (at shear rate $21 \mathrm{~s}^{-1}$ ) increased from $16 \mathrm{mPa} \cdot \mathrm{s}$ at $0.2 \% \mathrm{w} / \mathrm{v}$ to $3190 \mathrm{mPa} \cdot \mathrm{s}$ at $1.2 \% \mathrm{w} / \mathrm{v}$; whereas, the consistency of $\mathrm{KC}$ exhibited an increase from $33 \pm 1 \mathrm{mPa} \cdot \mathrm{s}^{n}$ to $21890 \pm 48 \mathrm{mPa} \cdot \mathrm{s}^{n}$ as the concentration was increased from 0.2 to $1.2 \% \mathrm{w} / \mathrm{v}$. This behaviour is consistent with observations of other polysaccharides $[45,46]$ and polymers in general [47].

Table 1 shows that KC solutions with a concentration $<0.5 \% \mathrm{w} / \mathrm{v}$ have power-index values of $\sim 0.8$. However, for higher concentrations the solutions become more shear-thinning ( $n$ decreases), and thicker ( $K$ increases). Figure $1 \mathrm{c}$ shows a sharp increase in the apparent viscosity of the KC solution 

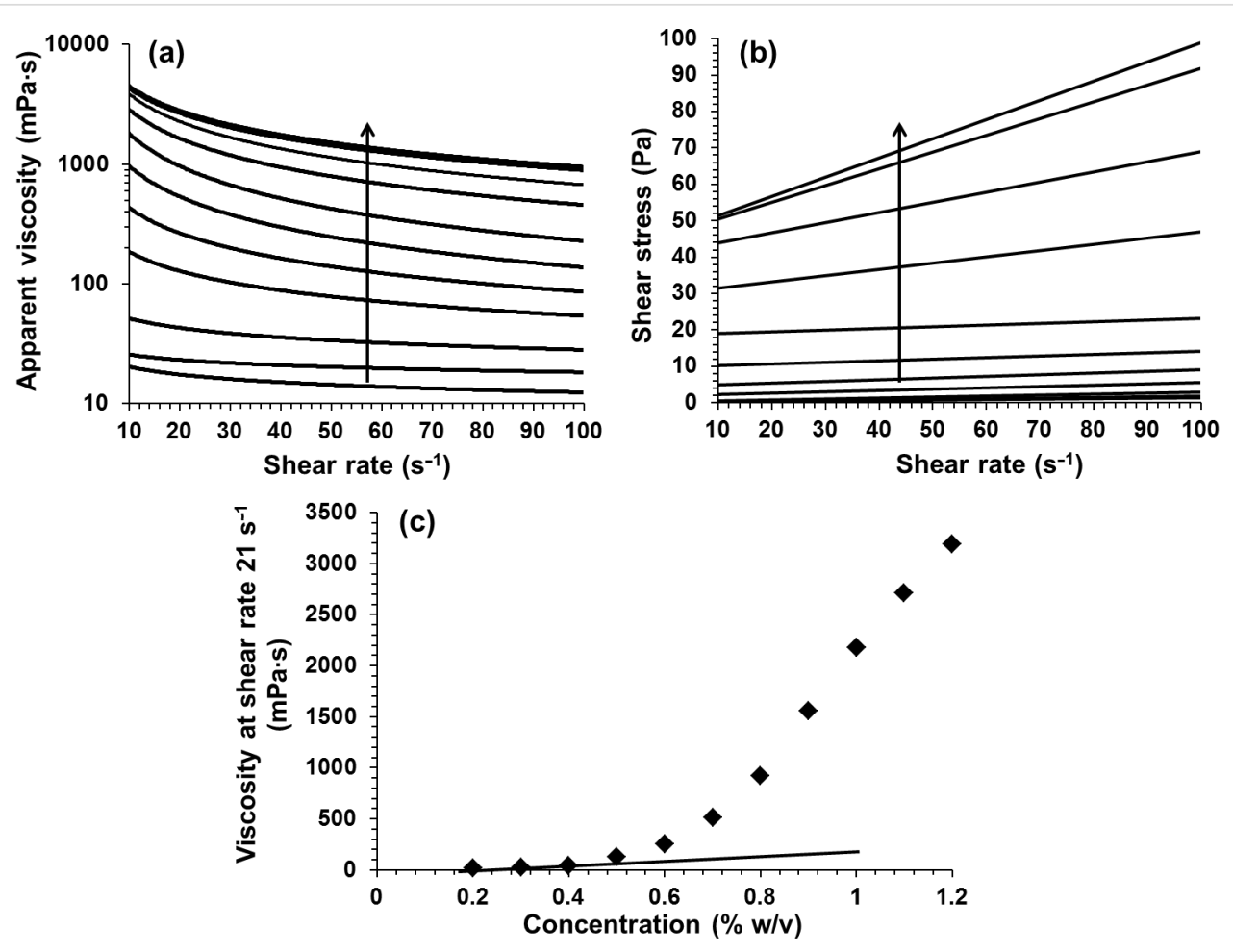

Figure 1: Effect of increasing concentration on (a) the viscosity and (b) the shear stress versus shear rate of KC solutions. The lines in (a) and (b) are fits to Equation 1 and Equation 2, respectively (measured data points omitted for clarity). The arrows indicate the direction of increase in KC concentration $(0.2-1.2 \% \mathrm{w} / \mathrm{v})$. (c) Viscosity at shear rate $21 \mathrm{~s}^{-1}$ as a function of concentration of $\mathrm{KC}$. All samples were measured at $21^{\circ} \mathrm{C}$. The straight line in (c) indicates the rate of increase at the lower concentrations.

around $0.5 \% \mathrm{w} / \mathrm{v}$, which is characteristic of dilute to semidilute transition.

The relation between shear stress and shear rate for IC solutions at different concentrations is shown in Figure 1b. It can be seen that $\mathrm{KC}$ solutions exhibit a yield point, i.e., the viscous $\mathrm{KC}$ solutions start to flow only when a certain amount of force is applied. This point can be determined by using approximations such as the Bingham model [44]:

$$
\tau=\tau_{\mathrm{B}}+\eta_{\mathrm{B}} s
$$

where $\tau_{\mathrm{B}}$ and $\eta_{\mathrm{B}}$ indicate the Bingham yield point and Bingham flow coefficient, respectively. Although the values obtained by

Table 1: Summary of rheology analysis of KC solutions at different concentrations $(c)$. Consistency $(K)$ and power-law index $(n)$ values were obtained through curve fitting with the power-law model (Equation 1). Bingham yield point $\left(\tau_{B}\right)$ and Bingham flow coefficient $\left(\eta_{B}\right)$ values were obtained by using the Bingham model (Equation 2). Values for all solutions were obtained over a shear-rate range of $10-100 \mathrm{~s}^{-1}$ and $21^{\circ} \mathrm{C}$.

\begin{tabular}{lllll}
$c(\% \mathrm{w} / \mathrm{v})$ & $K\left(\mathrm{mPa} \cdot \mathrm{s}^{n}\right)$ & $n$ & $\mathrm{~T}_{\mathrm{B}}(\mathrm{Pa})$ & $\eta_{\mathrm{B}}(\mathrm{Pa} \cdot \mathrm{s})$ \\
\hline 0.2 & $33 \pm 1$ & $0.79 \pm 0.01$ & $0.11 \pm 0.01$ & $0.012 \pm 0.001$ \\
0.3 & $36 \pm 1$ & $0.85 \pm 0.01$ & $0.11 \pm 0.01$ & $0.018 \pm 0.001$ \\
0.4 & $94 \pm 1$ & $0.74 \pm 0.01$ & $0.37 \pm 0.01$ & $0.025 \pm 0.001$ \\
0.5 & $637 \pm 1$ & $0.46 \pm 0.01$ & $1.88 \pm 0.05$ & $0.037 \pm 0.001$ \\
0.6 & $2158 \pm 2$ & $0.30 \pm 0.01$ & $4.49 \pm 0.06$ & $0.044 \pm 0.001$ \\
0.7 & $6725 \pm 9$ & $0.16 \pm 0.01$ & $9.87 \pm 0.05$ & $0.044 \pm 0.001$ \\
0.8 & $14030 \pm 12$ & $0.11 \pm 0.01$ & $18.53 \pm 0.18$ & $0.047 \pm 0.001$ \\
0.9 & $17718 \pm 6$ & $0.21 \pm 0.01$ & $29.79 \pm 0.39$ & $0.173 \pm 0.006$ \\
1.0 & $20506 \pm 42$ & $0.24 \pm 0.01$ & $41.08 \pm 0.89$ & $0.279 \pm 0.015$ \\
1.1 & $21058 \pm 32$ & $0.32 \pm 0.01$ & $46.78 \pm 1.21$ & $0.462 \pm 0.019$ \\
1.2 & $21890 \pm 48$ & $0.33 \pm 0.01$ & $46.08 \pm 0.54$ & $0.529 \pm 0.008$
\end{tabular}


using the Bingham model are dependent on the shear-rate range, it provides a good approximation for the determination of yield points [44]. The model shows that, over a shear-rate range of $10-100 \mathrm{~s}^{-1}$, the Bingham yield point and Bingham flow coefficient significantly increased with concentration. For example, the Bingham yield point of the KC solution $(0.2 \% \mathrm{w} / \mathrm{v})$ was $0.11 \pm 0.01 \mathrm{~Pa}$ compared to $46.08 \pm 0.54 \mathrm{~Pa}$ at a higher concentration $(1.2 \% \mathrm{w} / \mathrm{v})$, as shown in Table 1 . Thus, it is clear that an increase in concentration results in an increase in Bingham yield point and Bingham flow coefficient.

It is well-known that rheology through dynamic modulus measurements can be used to determine the sol-gel transition of polymer solutions. A larger loss modulus $\left(G^{\prime \prime}\right)$ than storage modulus $\left(G^{\prime}\right)$ in the linear viscoelastic region is indicative of solution-like behaviour. Whereas, the reverse $\left(G^{\prime}>G^{\prime \prime}\right)$ is in- dicative of gel-like behaviour [44]. The KC solutions with concentrations below $0.5 \% \mathrm{w} / \mathrm{v}$ exhibited lower $\mathrm{G}^{\prime}$ values than $\mathrm{G}^{\prime \prime}$ values (Figure $2 \mathrm{a}-\mathrm{c}$ ). As expected, by increasing the concentration, the loss and storage moduli increased (Figure 2d-e), but two distinct rates of increase were observed. Figure $2 \mathrm{f}$ shows this data expressed in terms of the loss factor, $\tan \delta=\mathrm{G}^{\prime \prime} / \mathrm{G}^{\prime}$ at a fixed shear-strain value (1.47\%). Values of $\tan \delta>1$ indicate solution-like behaviour, whereas $\tan \delta$ values $\leq 1$ point towards gel-like behaviour. These results provide further evidence for a dilute to semidilute transition for $\mathrm{KC}$ concentrations around $0.5 \% \mathrm{w} / \mathrm{v}$.

\section{Optimisation of sonication time}

A $\mathrm{KC}$ concentration $(0.5 \% \mathrm{w} / \mathrm{v})$ in the dilute range was selected to optimise the dispersion of CNTs at a concentration of $0.10 \% \mathrm{w} / \mathrm{v}$. The optimum sonication time is defined as the
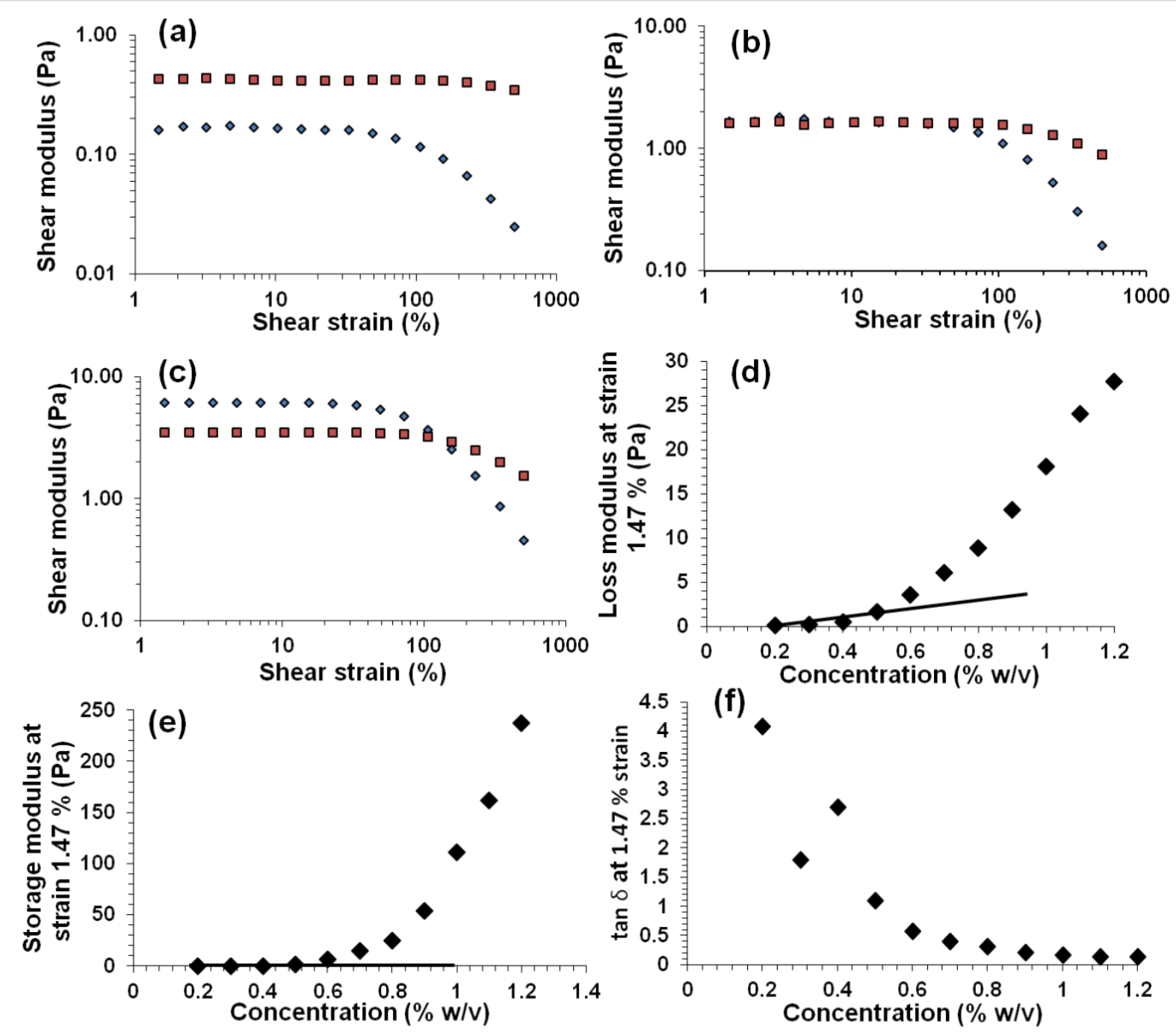

Figure 2: (a-c) Storage ( $\mathrm{G}^{\prime}$, diamonds) and loss modulus ( $\mathrm{G}^{\prime \prime}$, squares) of $\mathrm{KC}$ solutions at concentrations of $0.4 \%, 0.5 \%$, and $0.6 \%$ w/v, respectively; ( $d$ and $e$ ) loss and storage modulus of KC versus solution concentration at $1.47 \%$ shear strain, and (f) loss factor (tan $\delta=G^{\prime \prime} / G^{\prime}$ ) versus concentration for $\mathrm{KC}$ at $1.47 \%$ shear strain. The straight lines in ( $\mathrm{d}$ and $\mathrm{e}$ ) indicate the rate of increase at the lower concentrations. 
minimum amount of time required to successfully disperse the CNTs [8]. This optimisation is necessary as it has been reported that excess sonication leads to damage of the nanotubes $[15,48]$. The optimum sonication time was determined as defined in [8], by establishing the time it takes for the UV-vis absorption intensity to level out and the visible aggregates to disappear. CNTs absorb at most wavelengths, while KCs do not exhibit any bands for wavelengths greater than $250 \mathrm{~nm}$; thus, by monitoring a wavelength in this range the dispersion of CNTs can be monitored.

Figure $3 \mathrm{a}$ and Figure $3 \mathrm{~b}$ show that the UV-vis absorbance intensity increases with sonication time, indicating that an increasing amount of CNTs became dispersed over time. The absorbance at an arbitrarily picked wavelength $(660 \mathrm{~nm})$ becomes independent of sonication after 20 and $35 \mathrm{~min}$ of sonication for MWNTs and SWNTs, respectively (Figure 3c). Optical microscopy revealed the presence of aggregates in the dispersions subjected to short sonication times ( $5 \mathrm{~min}$ ), see Figure $3 \mathrm{~d}$. In contrast, after 20 and $35 \mathrm{~min}$ of sonolysis no aggregates were visible, suggesting that homogenous dispersions were achieved. Therefore, these sonication times (20 and 35 minutes) were selected as being optimal for ensuring that the MWNTs and SWNTs were well dispersed in the KC solution. Conversion of sonication time to energy shows that achieving complete dispersion of MWNTs and SWNTs requires $14.4 \pm$ $0.8 \mathrm{~kJ}(\sim 0.96 \mathrm{~kJ}$ per $\mathrm{mg})$ and $25.2 \pm 1.1 \mathrm{~kJ}(\sim 1.68 \mathrm{~kJ}$ per $\mathrm{mg})$, respectively (inset in Figure 3c), i.e. SWNTs are 1.75 times more costly to disperse than are MWNTs.

\section{Stability and rheology of optimised disper- sions}

Wet-processing methods, such as vacuum filtration and evaporative casting, require dispersions that are stable for several days. Stability was assessed by monitoring of the UV-vis absorbance as a function of time. Figure $4 \mathrm{a}$ shows that the $\mathrm{KC}-\mathrm{CNT}$ dispersions are reasonably stable for a period of at least 10 days. In addition, these dispersions appeared to be stable after two months of storage under controlled conditions $\left(21^{\circ} \mathrm{C}, \mathrm{RH}=\right.$ $45 \%$, Figure $4 b$ ).
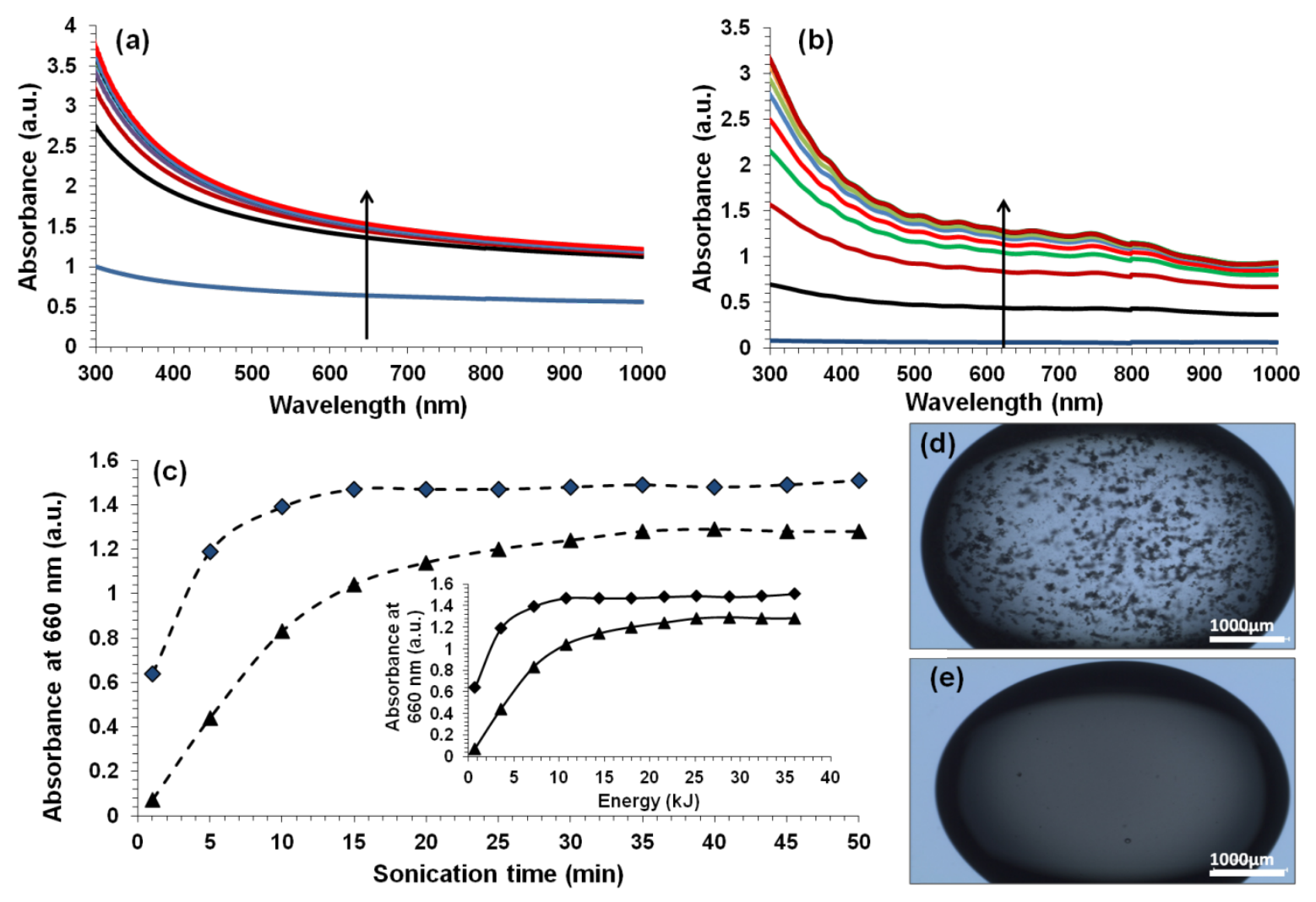

Figure 3: Effect of increasing sonication time on the UV-visible absorption spectrum of a dispersion containing (a) $0.10 \%$ w/v MWNTs and $0.50 \%$ w/V $\mathrm{KC}$ and (b) $0.10 \% \mathrm{w} / \mathrm{v}$ SWNTs and $0.50 \% \mathrm{w} / \mathrm{v} \mathrm{KC}$. (c) Absorbance at $660 \mathrm{~nm}$ versus sonication time and energy (inset) for KC-MWNT (diamonds) and KC-SWNT (triangles) dispersions. (d and e) KC-SWNTs after 5 and 35 minutes sonication, respectively. All samples were measured at $21^{\circ} \mathrm{C}$. Arrows indicate increasing sonication time. 

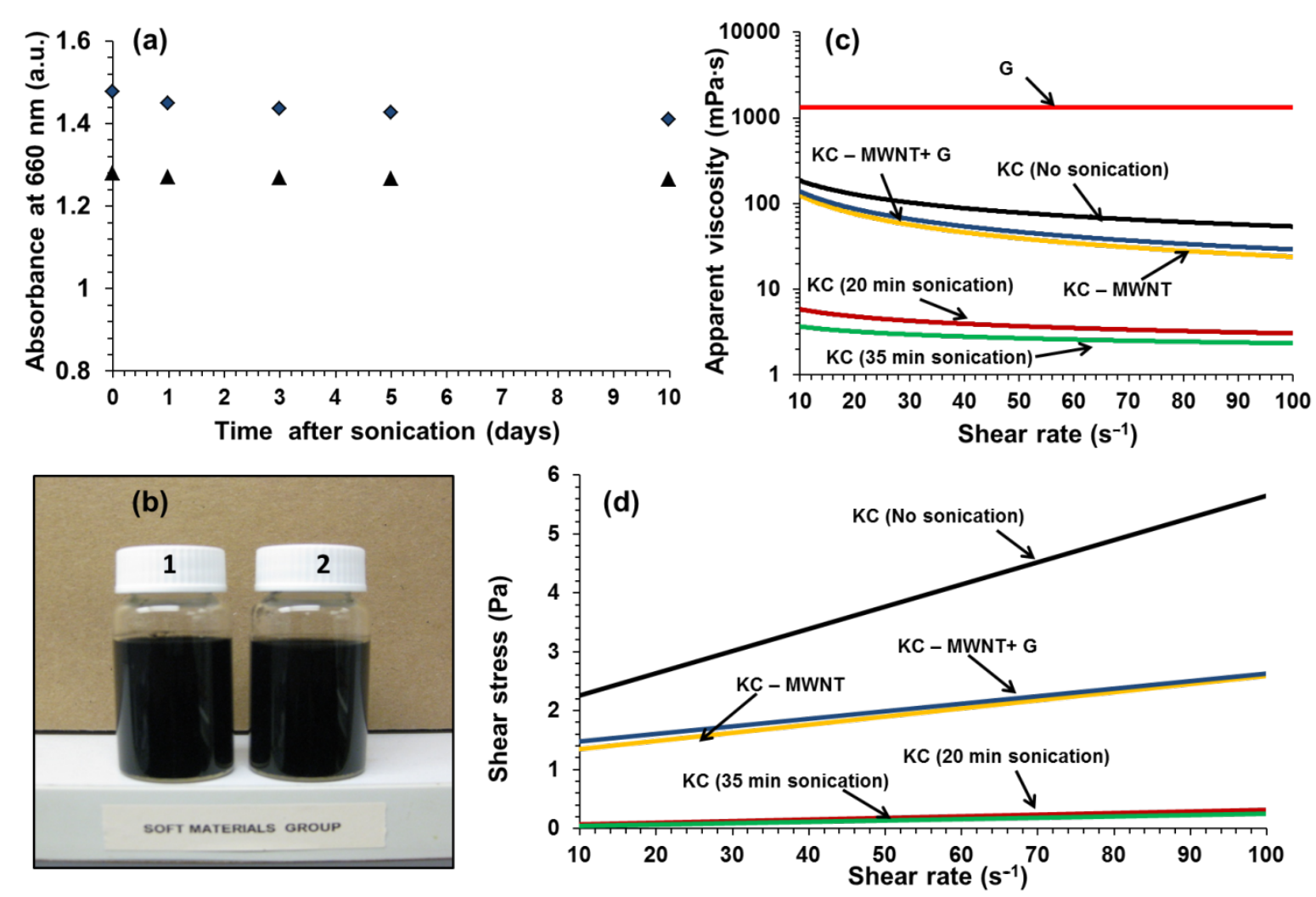

Figure 4: (a) UV-vis absorbance at $21{ }^{\circ} \mathrm{C}$ and at $660 \mathrm{~nm}$ wavelength for MWNT (diamonds) and SWNT (triangles) dispersions as a function of time. (b) Photographs of KC-MWNT (1) and KC-SWNT (2) dispersions after being left undisturbed for two months. (c) Apparent viscosity as a function of shear rate for undiluted glycerin $(G), \mathrm{KC}$ solutions $(0.5 \% \mathrm{w} / \mathrm{v})$ at different sonication times and $\mathrm{KC}-\mathrm{CNTs}$ ( $\mathrm{KC}$ concentration $=0.5 \% \mathrm{w} / \mathrm{v}$, CNT concentration $=0.1 \% \mathrm{w} / \mathrm{v}$ ) dispersions. (d) Shear stress versus shear rate of unsonicated KC, at different sonication times of KC solutions and KC-CNTs dispersions. The lines in (c) and (d) are fits to Equation 1 and Equation 2, respectively.

The flow curves of $\mathrm{KC}-\mathrm{CNT}$ dispersions and sonicated $\mathrm{KC}$ solutions are shown in Figure $4 \mathrm{~b}$ and Figure $4 \mathrm{c}$. It is clear that the apparent viscosity and consistency of $\mathrm{KC}$ solutions decreased significantly during sonication, while the value of the power-law index increased (Table 2). For example, over 35 minutes of sonication the consistency decreased from
$637.4 \pm 4.4 \mathrm{mPa} \cdot \mathrm{s}^{n}$ to $5.8 \pm 0.1 \mathrm{mPa} \cdot \mathrm{s}^{n}$, while $n$ increased from 0.46 to 0.80 . This suggests that sonication results in solutions that are thinner ( $K$ decreases) and less shear-thinning ( $n$ increases). This is in excellent agreement with previous observations, i.e., sonolysis reduces the molecular weight of the biopolymer, and this is responsible for the observed reduction in

Table 2: Summary of rheological analysis over a shear-rate range of $10-100 \mathrm{~s}^{-1}$ at $21{ }^{\circ} \mathrm{C}$ for $\mathrm{KC}$ solutions, and KC-CNT and KC-CNT-G dispersions for different sonication times (ST). Concentrations of KC, CNT and G are $0.5 \% \mathrm{w} / \mathrm{v}, 0.10 \% \mathrm{w} / \mathrm{v}$ and $0.25 \% \mathrm{w} / \mathrm{v}$, respectively. Consistency ( $K$ ) and power-law index $(n)$ values were obtained through curve fitting with the power-law model (Equation 1$)$. Bingham yield point ( $\mathrm{T}_{\mathrm{B}}$ ) and Bingham flow coefficient $\left(\eta_{B}\right)$ values were obtained using the Bingham model (Equation 2).

\begin{tabular}{llllll} 
Sample & ST $(\min )$ & $K\left(\mathrm{mPa} \cdot \mathrm{s}^{n}\right)$ & $n$ & $\mathrm{~T}_{\mathrm{B}}(\mathrm{Pa})$ & $1.88 \pm 0.17$ \\
\hline KC & 0 & $637 \pm 4$ & $0.46 \pm 0.01$ & $0.047 \pm 0.003$ \\
KC & 20 & $11.2 \pm 0.2$ & $0.72 \pm 0.01$ & $0.04 \pm 0.01$ & $0.003 \pm 0.001$ \\
KC & 35 & $5.8 \pm 0.1$ & $0.80 \pm 0.01$ & 0.01 & $0.002 \pm 0.001$ \\
G & 0 & $1320.0 \pm 0.1$ & $0.99 \pm 0.01$ & $1.21 \pm 0.02$ & $1.314 \pm 0.002$ \\
KC-MWNT & 20 & $648.5 \pm 4.4$ & $0.28 \pm 0.01$ & $1.35 \pm 0.01$ & $0.014 \pm 0.001$ \\
KC-MWNT-G & 20 & $662.9 \pm 5.7$ & $0.32 \pm 0.01$ & $1.29 \pm 0.01$ & $0.013 \pm 0.001$ \\
KC-SWNT & 35 & $814.4 \pm 4.4$ & $0.21 \pm 0.01$ & $0.010 \pm 0.001$ & $0.014 \pm 0.001$
\end{tabular}


apparent viscosity $[8,11,49]$. The addition of CNTs resulted in dispersions that were thicker ( $K$ increases) and more shear-thinning ( $n$ decreases) than the corresponding sonicated KC solutions (Table 2). Similar observations were made for the Bingham parameters, i.e., sonolysis reduced the $\tau_{B}$ and $\eta_{B}$ values, while the addition of CNT resulted in increased values. As expected, the addition of glycerin did not dramatically affect the flow properties of the KC-CNT dispersions. Glycerin is a Newtonian fluid, i.e., $n \sim 1$ indicating that its viscosity is independent of the shear rate (Table 2 ).

\section{Electrical conductivity of films}

Free-standing films were prepared by evaporative casting and vacuum filtration of $\mathrm{KC}-\mathrm{CNT}$ dispersions. All films exhibited linear $I-V$ characteristics, i.e., ohmic behaviour (Figure $5 \mathrm{a}$ ). The total resistance $\left(R_{\mathrm{T}}\right)$ increased with channel length (Figure $5 \mathrm{~b}$ ), and was found to scale linearly with sample length according to $[9,27]$

$$
R_{\mathrm{T}}=\frac{1}{\sigma A} l+R_{\mathrm{C}}
$$

where $l, A, \sigma$ and $R_{\mathrm{C}}$ are the length, cross-sectional area, electrical conductivity and contact resistance of the sample, respectively. The slope of the straight-line fit to Equation 3 can then be used to calculate the bulk conductivities (Table 3). Due to the difference in the density values of MWNTs $\left(2.15 \mathrm{~g} / \mathrm{cm}^{3}\right)$ and SWNTs $\left(1.5 \mathrm{~g} / \mathrm{cm}^{3}\right)$ it is not appropriate to compare in terms of
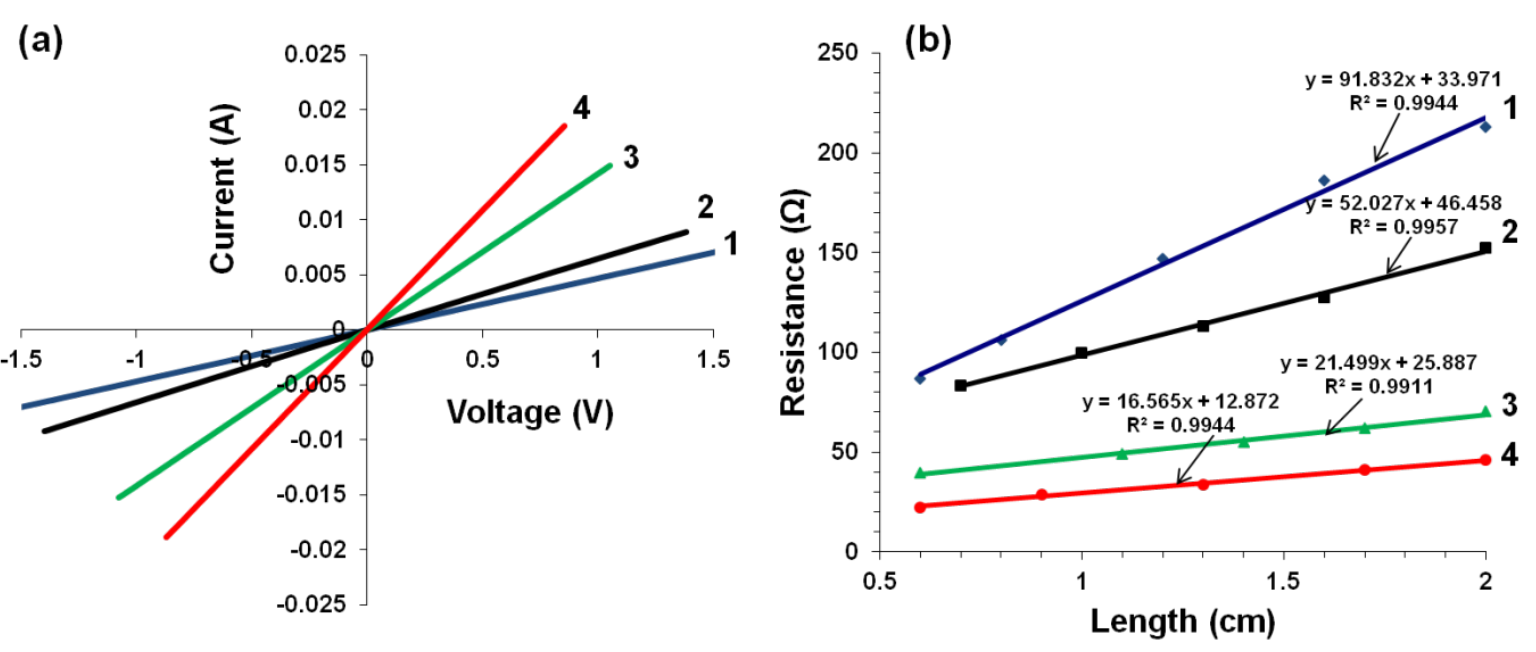

Figure 5: (a) $I-V$ characteristics for $\mathrm{KC}-\mathrm{CNT}$ (channel length $2 \mathrm{~cm}$ ) and (b) resistance as a function of length for KC-CNT composite films prepared by evaporative casting and vacuum filtration of KC-CNT dispersions. Numbers 1 and 2 are KC-MWNT and KC-SWNT composite films, respectively, prepared by evaporative cast method. Numbers 3 and 4 are KC-MWNT and KC-SWNT composite films, respectively, prepared by the vacuum-filtration method. The straight lines in (b) are fits to Equation 3.

Table 3: Effect of preparation method and addition of glycerin $(G)$ on the conductivity $(\sigma)$ of KC-CNT films prepared by evaporative casting (E1-4) and vacuum filtration (B1-4) methods. CNT mass $\left(M_{\mathrm{f}}\right)$ and volume $\left(V_{\mathrm{f}}\right)$ fractions values are calculated by using Equation 4 and Equation 5 , respectively. The naming of the dispersions indicates the concentrations of biopolymer, CNTs and glycerin, i.e., "KC05-MW01-G025" corresponds to dispersion with $\mathrm{KC}, \mathrm{MWNT}$ and $\mathrm{G}$ concentrations of $0.5 \% \mathrm{w} / \mathrm{v}, 0.1 \% \mathrm{w} / \mathrm{v}$ and $0.25 \% \mathrm{w} / \mathrm{v}$, respectively.

\begin{tabular}{|c|c|c|c|c|c|}
\hline Film & Dispersion & $\theta$ & $M_{\mathrm{f}}$ & $V_{f}$ & $\sigma(\mathrm{S} / \mathrm{cm})$ \\
\hline E1 & KC05-MW01 & $64.5 \pm 1.1$ & 0.17 & 0.10 & $8.6 \pm 1.6$ \\
\hline E2 & KC05-MW01-G025 & $56.0 \pm 1.1$ & 0.12 & 0.071 & $5.0 \pm 0.9$ \\
\hline E3 & KC05-SW01 & $62.7 \pm 1.1$ & 0.17 & 0.13 & $7.4 \pm 0.9$ \\
\hline E4 & KC05-SW01-G025 & $50.9 \pm 1.4$ & 0.12 & 0.099 & $2.9 \pm 0.5$ \\
\hline B1 & KC015-MW003 & $76.9 \pm 0.8$ & - & - & $16.4 \pm 1.6$ \\
\hline B2 & KC015-MW003-G0075 & $72.4 \pm 0.8$ & - & - & $14.5 \pm 1.7$ \\
\hline B3 & KC015-SW003 & $79.5 \pm 2.0$ & - & - & $25.4 \pm 1.6$ \\
\hline B4 & KC015-SW003-G0075 & $73.0 \pm 0.8$ & - & - & $17.9 \pm 1.9$ \\
\hline
\end{tabular}


mass fraction, but rather the volume fraction is more suitable. The CNT mass $\left(M_{\mathrm{f}}\right)$ and volume $\left(V_{\mathrm{f}}\right)$ fractions of films prepared by evaporative casting were obtained as follows:

$$
M_{\mathrm{f}}=\frac{m_{\mathrm{CNT}}}{m_{\mathrm{total}}},
$$

$V_{\mathrm{f}}=\left(m_{\mathrm{CNT}} / \rho_{\mathrm{CNT}}\right) /\left(m_{\mathrm{KC}} / \rho_{\mathrm{KC}}+m_{\mathrm{G}} / \rho_{\mathrm{G}}+m_{\mathrm{CNT}} / \rho_{\mathrm{CNT}}\right)$,

where $m_{\mathrm{CNT}}, m_{\mathrm{KC}}, m_{\mathrm{G}}, m_{\mathrm{total}}, \rho_{\mathrm{CNT}}, \rho_{\mathrm{KC}}$, and $\rho_{\mathrm{G}}$, are the mass of CNT, KC, and G, their total mass, and the densities of CNT, $\mathrm{KC}$ and $\mathrm{G}$, respectively. The density value of $\mathrm{KC}$ was determined experimentally $\left(1.22 \pm 0.06 \mathrm{~g} / \mathrm{cm}^{3}\right)$ and the well-known density values of $\mathrm{G}\left(1.26 \mathrm{~g} / \mathrm{cm}^{3}\right)$ and the CNTs were used to calculate the CNT volume fraction. It was found that evaporation-cast MWNT films exhibited higher conductivity values compared to SWNT films at a similar volume fraction, $V_{\mathrm{f}}$ 0.10 . The conductivity of SWNT films with a higher volume fraction $\left(V_{\mathrm{f}}=0.13\right)$ was still lower than that of a MWNT film with $V_{\mathrm{f}}=0.10$. These observations are in agreement with our previous observations for biopolymer composite materials [8].

It was not possible to calculate the CNT mass or volume fractions for buckypapers, as it is unknown what was lost during the filtration process. In our previous work, we showed that the contact angle increases linearly with CNT mass and volume fraction [8]. The contact angle of all buckypaper materials is higher than those of evaporation-cast films (Table 3). This could suggest that the CNT mass/volume fraction in the buckypapers is higher than those of the evaporation-cast samples. This is supported by the difference in the surface morphology as observed in SEM images (Figure 6), i.e., the biopolymer coverage of the CNTs is more extensive for evaporation-cast films than for buckypapers. The lower degree of coverage can be attributed to the partial removal of KC and CNTs during the vacuum filtration process. These observations are supported by the difference in conductivity between casted $(7.4 \mathrm{~S} / \mathrm{cm})$ and buckypaper (25.4 S/cm) SWNT composite films, with similar results for MWNT composite films. Hence, it is clear that the partial removal of $\mathrm{KC}$ results in an increase in the conductivity. The conductivity values of KC-SWNT buckypapers (25.4 \pm $1.6 \mathrm{~S} / \mathrm{cm})$, were higher compared to those of the $\mathrm{KC}-\mathrm{MWNT}$ buckypapers $(16.4 \pm 1.6 \mathrm{~S} / \mathrm{cm})$.

Incorporation of the hydrophilic plasticizer glycerin in the composite films reduced their conductivity and contact angle values. For example, the conductivity of a KC-SWNT film prepared by the evaporative-casting method decreased from
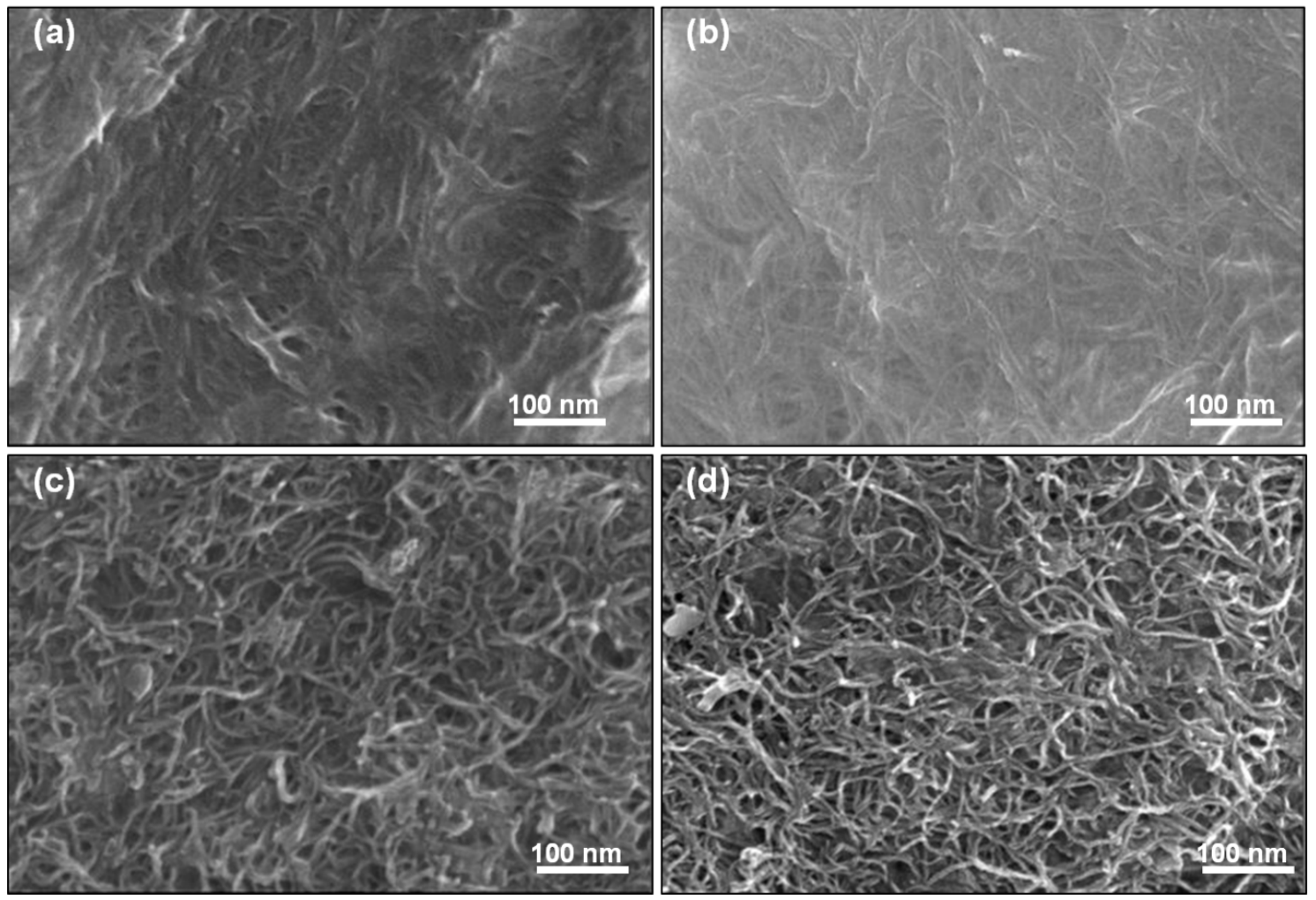

Figure 6: SEM image of (a) KC-CNT and (b) KC-CNT-G composite films prepared by the evaporative-casting method. (c) KC-CNT and (d) KC-CNT-G composite films prepared by the vacuum-filtration method. Contact angle values for (a-d) are $64^{\circ}, 56^{\circ}, 77^{\circ}$ and $72^{\circ}$, respectively. 
$7.4 \mathrm{~S} / \mathrm{cm}$ to $2.9 \mathrm{~S} / \mathrm{cm}$ through the addition of glycerin. This lowering of the conductivity suggests that glycerin may affect the number of conducting pathways or junctions in the nanotube network.

\section{Mechanical properties of films}

The mechanical characteristics of the free-standing films prepared by evaporative casting and vacuum filtration of $\mathrm{KC}-\mathrm{CNT}$ dispersions are shown in Figure 7. Sonication of the $\mathrm{KC}$ solution prior to film formation reduced the mechanical characteristics of these films. The sonication-induced reduction in the molecular weight resulted in films with reduced values of tensile strength $(T S=20 \mathrm{MPa})$, strain-at-break $(\gamma=2 \%)$ and Young's modulus ( $E=1165 \mathrm{MPa})$ (Table 4).

Table 4: Summary of the mechanical properties of composite films prepared by evaporative casting (E1-4) and vacuum filtration (B1-4). Young's modulus $(E)$, tensile strength $(T S)$ and strain-at-break $(\mathrm{V})$. E1-4 and B1-4 refer to composite films listed in Table 3.

\begin{tabular}{llll} 
Film & $E(\mathrm{MPa})$ & TS $(\mathrm{MPa})$ & $Y(\%)$ \\
\hline E1 & $1414 \pm 43$ & $32 \pm 4$ & $5.1 \pm 0.7$ \\
E2 & $1031 \pm 40$ & $21 \pm 2$ & $7.1 \pm 0.8$ \\
E3 & $1640 \pm 45$ & $27 \pm 3$ & $3.3 \pm 0.5$ \\
E4 & $434 \pm 29$ & $18 \pm 2$ & $4.8 \pm 0.6$ \\
B1 & $2184 \pm 77$ & $36 \pm 3$ & $2.5 \pm 0.6$ \\
B2 & $1142 \pm 61$ & $32 \pm 3$ & $4.0 \pm 1.0$ \\
B3 & $2848 \pm 81$ & $44 \pm 4$ & $2.3 \pm 0.8$ \\
B4 & $1228 \pm 49$ & $39 \pm 3$ & $4.5 \pm 1.0$
\end{tabular}

The addition of CNTs resulted in increases in the $T S, \gamma$ and $E$ values for both MWNTs and SWNTs compared to the corresponding values for the sonicated $\mathrm{KC}$ film (Table 4). This can be attributed to the mechanical reinforcement effect of incorpor- ating CNTs into the polymer matrix [32,50]. Films produced by the evaporative-casting method exhibited higher $E$ and $T S$ values compared to films produced by vacuum filtration. In contrast, films prepared by the evaporative-casting method exhibit higher strain-at-break values than do films produced by vacuum filtration. Hence, it is clear that films produced by vacuum filtration are more robust and less ductile compared to films prepared by the evaporative-casting method.

Incorporation of a plasticizer (glycerin) resulted in a reduction of the $E$ and $T S$ values but improved ductility. For example, the $\gamma$ value for KC-MWNTs films with glycerin prepared by the evaporative-cast method is $7.1 \%$ compared to $5.1 \%$ for the same film without glycerin. This suggests that glycerin is a good material for improving the mechanical handleability of these CNT composite films.

\section{Sensing properties of films}

The sensitivity $(S)$ of films against humidified air, and $\mathrm{H}_{2}$ and $\mathrm{CH}_{4}$ gases was investigated by monitoring the resistance as a function of time [51]:

$$
S(\%)=\left(\frac{\left|R_{\mathrm{g}}-R_{\mathrm{a}}\right|}{R_{\mathrm{a}}}\right) \times 100 \%,
$$

where $R_{\mathrm{a}}$ and $R_{\mathrm{g}}$ represent the resistance of the film before and during exposure to the target gas (humidified air, $\mathrm{H}_{2}$ and $\mathrm{CH}_{4}$ ), respectively. The sensitivity of the films to humidity was investigated over a relative humidity change from $40 \%$ to $90 \%$. All films responded to the change in humidity, but it was not possible to detect any response after exposure to $\mathrm{H}_{2}$ and $\mathrm{CH}_{4}$ gases at $25{ }^{\circ} \mathrm{C}$ (Figure 8). The $\mathrm{KC}-\mathrm{MWNT}$ films displayed higher sensitivity to water vapour compared to the corres-
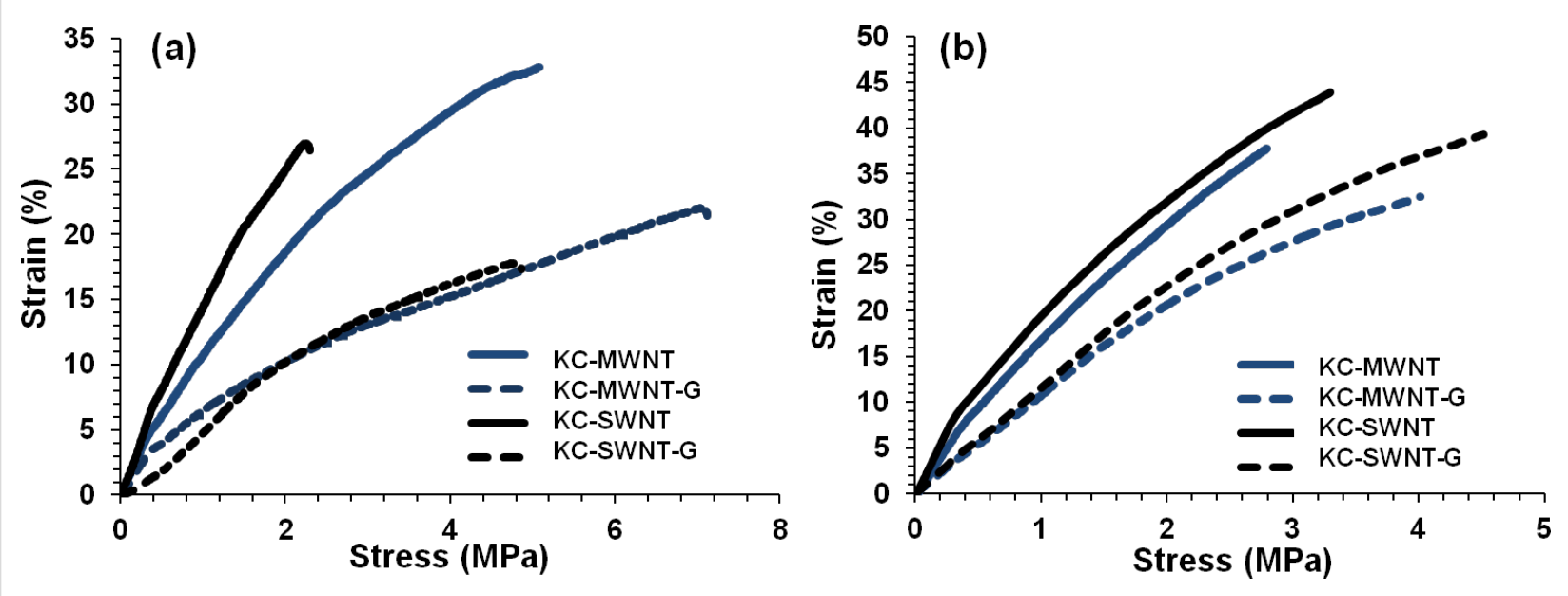

Figure 7: Stress-strain curves for films with and without glycerin prepared by (a) evaporative casting and (b) vacuum filtration methods. 

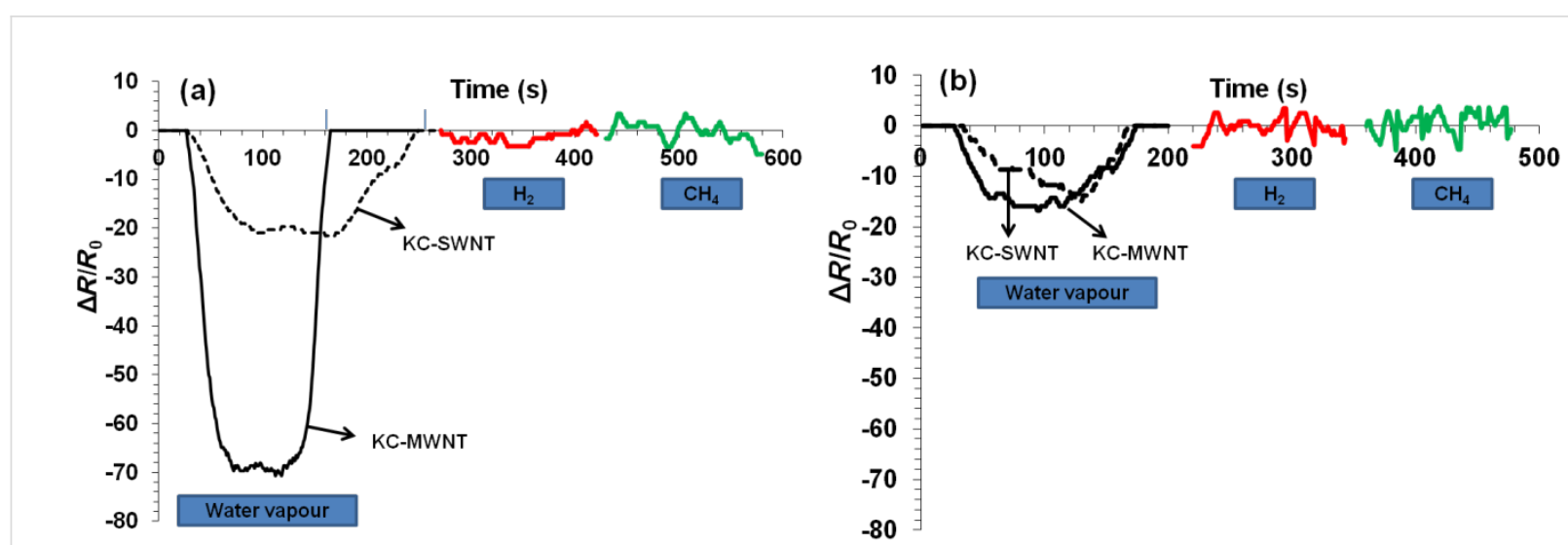

Figure 8: Response of KC-MWNT and KC-SWNT composite films to humidity change, $\mathrm{H}_{2}$ and $\mathrm{CH}_{4}$ gases (100 ppm in air) at operating temperature of $25^{\circ} \mathrm{C}$. Films prepared by (a) evaporative casting and (b) vacuum filtration.

ponding KC-SWNT films. For example, the sensitivity of MWNT films was $S=70 \pm 10 \%$ compared to $S=25 \pm 5 \%$ for SWNT films. However, the response/recovery times were faster for MWNT films (50 s) compared to SWNT films (70 s). The sensitivity was significantly reduced upon incorporation of glycerin, e.g., from $S=70 \pm 10 \%$ to $S=20 \pm 5 \%$ for MWNT composite films. Buckypaper films displayed lower sensitivity values of $\sim 17 \%$ (MWNT) and $\sim 15 \%$ (SWNT), respectively. It is likely that the observed differences in sensitivity can be attributed to the processing methods, i.e., the vacuum filtration process results in partial removal of $\mathrm{KC}$, as discussed above. It is not clear at present why MWNT films prepared by evaporative casting are about three times more sensitive compared to SWNT films. Further research is necessary to fully understand this.

\section{Conclusion}

In this work, rheological analysis was used to determine the appropriate concentration $(0.5 \% \mathrm{w} / \mathrm{v})$ for dispersing SWNTs and MWNTs by using the biopolymer KC. It was shown that MWNTs required less sonication compared to SWNTs, i.e., a lower amount of energy input. Rheological analysis revealed that an increasing amount of sonolysis reduced the flow characteristics (viscosity) of KC solutions, while addition of CNTs increased viscosity.

KC-MWNT films prepared by an evaporative-casting process displayed higher conductivity compared to KC-SWNT films. As expected, the conductivity of all buckypaper films was higher than films prepared by evaporative casting. It was observed that the incorporation of CNTs in the polymer matrix resulted in an increase in the values of the mechanical properties. The addition of a plasticizer (glycerin) improved the mechanical handleability, but at the cost of electrical conduct- ivity. Buckypaper films displayed superior electrical and mechanical characteristics (bar ductility) over evaporation-cast films, but they were less sensitive to changes in the humidity. MWNT films exhibited sensitivity to humidity as high as of $70 \%$, easily outperforming SWNT films. This work contributes toward the development of conducting biopolymer composite materials.

\section{Experimental \\ Materials}

The biopolymer iota-carrageenan $(\mathrm{KC}$, molecular weight range 350,000-800,000 g/mol, Genuvisco type CI-102, lot \# SKS2500) was donated by CP Kelco (USA). Multiwalled carbon nanotubes (MWNTs) produced by catalytic chemical vapour deposition were obtained from Nanocyl S.A. (Belgium, lot \# 090901). Single-walled carbon nanotubes (SWNTs), produced by high-pressure decomposition of carbon monoxide (HiPCO process), were purchased from Unidym Inc. (USA, lot \# P0348). Glycerin was obtained from Sigma Aldrich (USA, lot \# 033K0097). Methanol ( $\mathrm{CH}_{3} \mathrm{OH}$, lot \# 318-2.5L GL) was purchased from Ajax Finechem (Australia). Hydrophobic polytetrafluoroethylene (PTFE, pore size of $5 \mu \mathrm{m}$ ) filtration membranes were purchased from Micro Filtration Systems (USA). Milli-Q water was used in all experiments and prepared by using a Millipore filtration system (resistivity of 18.2 M $\Omega$ $\mathrm{cm})$.

\section{Preparation of solution and dispersion}

Solutions of KC were prepared by adding appropriate amounts of $\mathrm{KC}$ to $15 \mathrm{~mL}$ of Milli-Q water under stirring for $3 \mathrm{~h}$ at $\sim 70{ }^{\circ} \mathrm{C}$ (Figure 9a). Homogenous $\mathrm{KC}-\mathrm{CNT}$ dispersions (CNT concentration $=0.1 \% \mathrm{w} / \mathrm{v}$, Figure $9 \mathrm{a}$ ) were prepared by using a digital sonicator horn (Branson 450, Ultrasonics Corp.) with a probe diameter of $10 \mathrm{~mm}$, in pulse mode $(0.5 \mathrm{~s}$ on/off $)$ and a power output of $12 \mathrm{~W}$. During sonication the sample vial was 

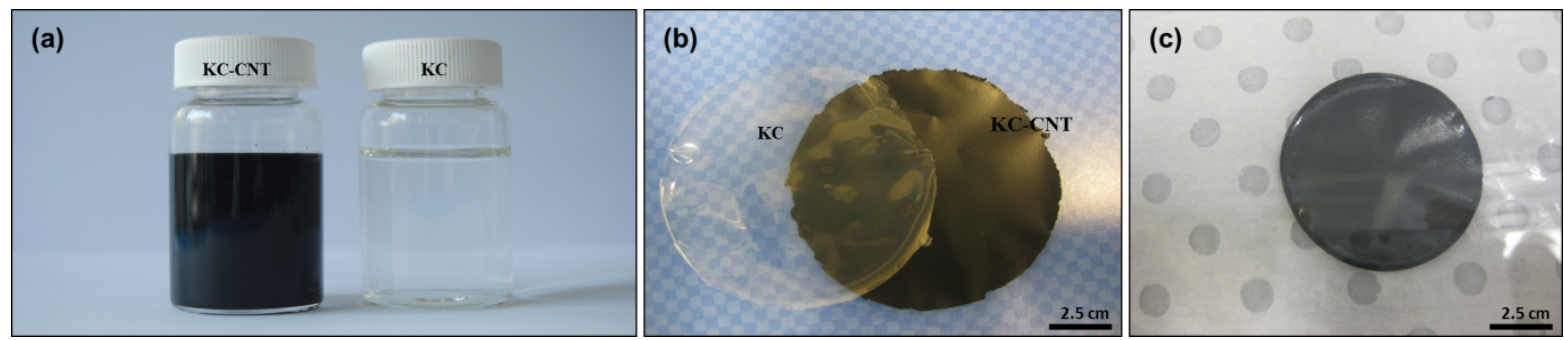

Figure 9: Photographs of (a) KC solution and KC-CNT dispersion, (b) films prepared by evaporative casting and (c) film prepared by vacuum-filtration method.

placed inside a water bath to keep the dispersion temperature constant. Glycerin $(\mathrm{G})$ was added to $\mathrm{KC}-\mathrm{CNT}$ dispersions at a concentration of $0.25 \% \mathrm{w} / \mathrm{v}$.

\section{Preparation of films by evaporative-casting method}

Free-standing films were prepared by evaporative casting of $\mathrm{KC}$ solution and $\mathrm{KC}-\mathrm{CNT}$ dispersions into the base of cylindrical plastic containers (polystyrene, diameter $=55 \mathrm{~mm}$ ), which were then dried under controlled conditions $\left(35^{\circ} \mathrm{C}\right.$, relative humidity, $\mathrm{RH}=45 \%$ ) in a temperature-humidity chamber (Thermoline Scientific) for $24 \mathrm{~h}$. The resulting films were peeled off the substrate to yield uniform free-standing films (Figure 9b).

\section{Preparation of films by vacuum-filtration method}

$\mathrm{KC}-\mathrm{CNT}$ dispersions were processed into buckypapers by using a vacuum-filtration method. Prior to the filtration the $\mathrm{KC}-\mathrm{CNT}$ dispersion was combined with $35 \mathrm{~mL}$ Milli-Q water and inverted to ensure complete mixing. The dispersions $(50 \mathrm{~mL})$ were drawn through a PTFE membrane filter (pore size $=5 \mu \mathrm{m})$ on a filtration unit (Millipore, diameter $=37 \mathrm{~mm}$ ) by using a vacuum pump (Vacuubrand $\mathrm{CVC} 2$ ). Once all of the dispersion had been filtered, the films were washed with $50 \mathrm{~mL}$ of Milli-Q water followed by $5 \mathrm{~mL}$ of methanol (99.8\%) and placed between absorbent paper sheets to dry under controlled conditions $\left(21^{\circ} \mathrm{C}, \mathrm{RH}=45 \%\right)$ for $24 \mathrm{~h}$. The films were then peeled off from the filtration membrane (Figure 9c).

\section{Characterization}

UV-visible-NIR absorption spectra of KC solutions and $\mathrm{KC}-\mathrm{CNTs}$ dispersions were obtained with a UV-vis-NIR spectrophotometer (Cary 500) by using a quartz cuvette (path length $=5 \mathrm{~mm}$ ). All solutions and dispersions were diluted by a factor of 10. Dispersions were imaged by using an optical microscope (LEICA Z16 APO) fitted with a digital camera (LEICA DFC280) and Leica Application Suite (version 3.1.0 R1) software. Rheological testing was conducted by using a parallel-plate rheometer (Anton Paar-Physica MCR 301) with a
$50 \mathrm{~mm}$ diameter probe head (cone angle $1^{\circ}$ ) at $21^{\circ} \mathrm{C}$. KC-CNT dispersions and $\mathrm{KC}$ solutions were analysed by using flow curves (viscosity and shear stress versus shear rate). The dynamic modulus was measured by using oscillatory strain sweeps at constant frequency.

For conductivity measurements, films were cut into strips $0.5 \mathrm{~cm}$ in width and $3 \mathrm{~cm}$ in length and contacted with copper electrodes $(3 \mathrm{M})$. Current $(I)$-voltage $(V)$ characteristics were obtained by measuring the current using a digital multimeter (Agilent 34410A) under a cycling potential applied by a waveform generator (Agilent 33220A). $I-V$ measurements were conducted under controlled ambient conditions $\left(21^{\circ} \mathrm{C}, \mathrm{RH}=\right.$ $45 \%$ ) as a function of film length, by repeatedly cutting the end of the strip, contacting with the electrodes and remeasuring the $I-V$ characteristics. Film thickness was determined with a Mitutoyo IP65 digital micrometer.

The mechanical properties of all films were obtained by using a dynamic mechanical analyser (DMA) Q800 (TA instruments). Measurements were carried out under ambient conditions $\left(21^{\circ} \mathrm{C}, \mathrm{RH}=45 \%\right)$ on rectangular strips (length $\left.=10 \mathrm{~mm}\right)$ at a cross-head speed of $0.1 \mathrm{~mm} / \mathrm{min}$. Tensile strength, strain-atbreak and Young's modulus were determined from the maximum stress, the strain at failure, and the slope of the initial linear part of the stress-strain curve, respectively.

Scanning electron microscope (SEM) images were acquired by using a JEOL JSM-7500FA. Samples were prepared by mounting small pieces of films onto a brass stub $\left(11 \times 5 \mathrm{~mm}^{2}\right)$ with double-sided, conductive carbon tape (Proscitech, Australia).

Contact-angle measurements were carried out by using the sessile drop method on a goniometer (Data Physics SCA20), which was fitted with a digital camera. The contact angles of $1 \mu \mathrm{L}$ Milli-Q water droplets on the surface of the samples were calculated after $30 \mathrm{~s}$ by using the accompanying Data Physics software (version SCA20.1). The mean contact angle was calcu- 
lated based on measurements performed on at least five water droplets.

The sensing properties of the films were investigated with a custom-built system [52]. The films are connected in series to a known resister $(909 \Omega)$ and a battery $(4.91 \mathrm{~V})$ to form a voltage-current-resistor $(V-I-R)$ electrical circuit as a prototype sensor. The sensitivity of the sensors was characterised by using measurements of the voltage drop across the known resistor and film under different environmental conditions, i.e., as a function of temperature and humidity, and by exposure to different gases $\left(\mathrm{H}_{2}\right.$ and $\left.\mathrm{CH}_{4}\right)$ at a concentration of $100 \mathrm{ppm}$ in air. For all measurements, air was used as the carrier gas. The chamber volume $(1000 \mathrm{~mL})$ ensures that the change of gas concentration was instantaneous, which is a prerequisite condition for the accurate measurements of response and recovery time of the sensor.

\section{Acknowledgments}

This work was funded by King Saud University (A. Aldalbahi), University of Wollongong, Australian Research Council (ARC) Centre of Excellence Program, ARC Future Fellowship (M. in het Panhuis) and NSF EPSCoR program (P. Feng). We thank M. Collins, R. Clark and P. Jackson (all CP Kelco) for the provision of materials and T. Romeo (University of Wollongong) for assistance with SEM measurements.

\section{References}

1. Jorio, A.; Dresselhaus, G.; Dresselhaus, M. S., Eds. Carbon Nanotubes: Advanced Topics in the Synthesis, Structure, Properties and Applications; Topics in Applied Physics, Vol. 111; Springer-Verlag: Berlin, 2008. doi:10.1007/978-3-540-72865-8

2. in het Panhuis, M. J. Mater. Chem. 2006, 16, 3598-3605. doi:10.1039/B606959B

3. Dresselhaus, M. S.; Dresselhaus, G.; Eklund, P. C. Science of Fullerenes and Carbon Nanotubes; Academic Press: San Diego, 1996.

4. Saito, R.; Dresselhaus, G.; Dresselhaus, M. S. Physical Properties of Carbon Nanotubes; Imperial College Press: London, 1998. doi:10.1142/9781860943799

5. Hamon, M. A.; Chen, J.; Hu, H.; Chen, Y.; Itkis, M. E.; Rao, A. M.; Eklund, P. C.; Haddon, R. C. Adv. Mater. 1999, 11, 834-840. doi:10.1002/(SICI)1521-4095(199907)11:10<834::AID-ADMA834>3.0. $\mathrm{CO} ; 2-\mathrm{R}$

6. Nuriel, S.; Liu, L.; Barber, A. H.; Wagner, H. D. Chem. Phys. Lett. 2005, 404, 263-266. doi:10.1016/j.cplett.2005.01.072

7. Sainz, R.; Small, W. R.; Young, N. A.; Vallés, C.; Benito, A. M.; Maser, W. K.; in het Panhuis, M. Macromolecules 2006, 39, 7324-7332. doi:10.1021/ma061587q

8. Aldalbahi, A.; in het Panhuis, M. Carbon 2012, 50, 1197-1208. doi:10.1016/j.carbon.2011.10.034

9. Boge, J.; Sweetman, L. J.; in het Panhuis, M.; Ralph, S. F. J. Mater. Chem. 2009, 19, 9131-9140. doi:10.1039/B914824H

10. Ferris, C. F.; in het Panhuis, M. Soft Matter 2009, 5, 3430-3437. doi:10.1039/B909795C
11. Granero, A. J.; Razal, J. M.; Wallace, G. G.; in het Panhuis, M. Adv. Funct. Mater. 2008, 18, 3759-3764. doi:10.1002/adfm.200890097

12. Hrapovic, S.; Male, K. B.; Liu, Y.; Luong, J. H. T. Anal. Lett. 2008, 41, 278-288. doi:10.1080/00032710701792737

13. Moulton, S. E.; Minett, A. I.; Murphy, R.; Ryan, K. P.; McCarthy, D.; Coleman, J. N.; Blau, W. J.; Wallace, G. G. Carbon 2005, 43, 1879-1884. doi:10.1016/j.carbon.2005.02.036

14. Razal, J. M.; Gilmore, K. J.; Wallace, G. G. Adv. Funct. Mater. 2008, 18, 61-66. doi:10.1002/adfm.200700822

15. Vaisman, L.; Wagner, H. D.; Marom, G. Adv. Colloid Interface Sci. 2006, 128-130, 37-46. doi:10.1016/j.cis.2006.11.007

16. Wang, J.; Musameh, M.; Lin, Y. J. Am. Chem. Soc. 2003, 125, 2408-2409. doi:10.1021/ja028951v

17. Bystrzejewski, M.; Huczko, A.; Lange, H.; Gemming, T.; Büchner, B.; Rümmeli, M. H. J. Colloid Interface Sci. 2010, 345, 138-142. doi:10.1016/j.jcis.2010.01.081

18. Duro, R.; Souto, C.; Gómez-Amoza, J. L.; Martínez-Pacheco, R.; Concheiro, A. Drug Dev. Ind. Pharm. 1999, 25, 817-829. doi:10.1081/DDC-100102244

19. Grossiord, N.; Regev, O.; Loos, J.; Meuldijk, J.; Koning, C. E. Anal. Chem. 2005, 77, 5135-5139. doi:10.1021/ac050358j

20. Islam, M. F.; Rojas, E.; Bergey, D. M.; Johnson, A. T.; Yodh, A. G. Nano Lett. 2003, 3, 269-273. doi:10.1021/nl025924u

21. Lin, Y.; Taylor, S.; Li, H.; Shiral Fernando, K. A.; Qu, L.; Wang, W.; Gu, L.; Zhou, B.; Sun, Y.-P. J. Mater. Chem. 2004, 14, 527-541. doi:10.1039/B314481J

22. O'Connell, M. J.; Bachilo, S. M.; Huffman, C. B.; Moore, V. C.; Strano, M. S.; Haroz, E. H.; Rialon, K. L.; Boul, P. J.; Noon, W. H.; Kittrell, C.; Ma, J.; Hauge, R. H.; Weisman, R. B.; Smalley, R. E. Science 2002, 297, 593-596. doi:10.1126/science.1072631

23. O'Connell, M. J.; Boul, P.; Ericson, L. M.; Huffman, C.; Wang, Y.; Haroz, E.; Kuper, C.; Tour, J.; Ausman, K. D.; Smalley, R. E. Chem. Phys. Lett. 2001, 342, 265-271. doi:10.1016/S0009-2614(01)00490-0

24. Star, A.; Stoddart, J. F.; Steuerman, D.; Diehl, M.; Boukai, A.; Wong, E. W.; Yang, X.; Chung, S.-W.; Choi, H.; Heath, J. R. Angew. Chem., Int. Ed. 2001, 40, 1721-1725. doi:10.1002/1521-3773(20010504)40:9<1721::AID-ANIE17210>3.0.CO ;2-F

25. Bandyopadhyaya, R.; Nativ-Roth, E.; Regev, O.; Yerushalmi-Rozen, R. Nano Lett. 2002, 2, 25-28. doi:10.1021/nl010065f

26. Polaczek, E.; Stobiński, L.; Mazurkiewicz, J.; Tomasik, P.; Kołoczek, H.; Lin, H.-M. Polimery 2007, 52, 34-38.

27. Ferris, C. J.; in het Panhuis, M. Soft Matter 2009, 5, 1466-1473. doi:10.1039/B818411A

28. Lu, L.; Chen, W. ACS Nano 2010, 4, 1042-1048. doi:10.1021/nn901326m

29. Songmee, N.; Singjai, P.; in het Panhuis, M. Nanoscale 2010, 2 , 1740-1745. doi:10.1039/CONR00259C

30. in het Panhuis, M.; Heurtematte, A.; Small, W. R.; Paunov, V. N. Soft Matter 2007, 3, 840-843. doi:10.1039/B704368F

31. Bauhofer, W.; Kovacs, J. Z. Compos. Sci. Technol. 2009, 69, 1486-1498. doi:10.1016/j.compscitech.2008.06.018

32. Coleman, J. N.; Khan, U.; Gun'ko, Y. K. Adv. Mater. 2006, 18, 689-706. doi:10.1002/adma.200501851

33. Kukovecz, Á.; Smajda, R.; Kónya, Z.; Kiricsi, I. Carbon 2007, 45, 1696-1698. doi:10.1016/j.carbon.2007.04.033

34. Whitby, R. L. D.; Fukuda, T.; Maekawa, T.; James, S. L.; Mikhalovsky, S. V. Carbon 2008, 46, 949-956. doi:10.1016/j.carbon.2008.02.028 
35. Claye, A. S.; Fischer, J. E.; Huffman, C. B.; Rinzler, A. G.; Smalley, R. E. J. Electrochem. Soc. 2000, 147, 2845-2852. doi:10.1149/1.1393615

36. Liu, T.; Sreekumar, T. V.; Kumar, S.; Hauge, R. H.; Smalley, R. E. Carbon 2003, 41, 2440-2442. doi:10.1016/S0008-6223(03)00245-8

37. Prokudina, N. A.; Shishchenko, E. R.; Joo, O.-S.; Hyung, K.-H.; Han, S.-H. Carbon 2005, 43, 1815-1819. doi:10.1016/j.carbon.2005.02.012

38. Rein, M. D.; Breuer, O.; Wagner, H. D. Compos. Sci. Technol. 2011, 71, 373-381. doi:10.1016/j.compscitech.2010.12.008

39. Campo, V. L.; Kawano, D. F.; da Silva, D. B., Jr.; Carvalho, I. Carbohydr. Polym. 2009, 77, 167-180. doi:10.1016/j.carbpol.2009.01.020

40. van de Velde, F.; Lourenço, N. D.; Pinheiro, H. M.; Bakker, M. Adv. Synth. Catal. 2002, 344, 815-835. doi:10.1002/1615-4169(200209)344:8<815::AID-ADSC815>3.0.CO;2$\mathrm{H}$

41. Buck, C. B.; Thompson, C. D.; Roberts, J. N.; Müller, M.; Lowy, D. R.; Schiller, J. T. PLoS Pathog. 2006, 2, e69. doi:10.1371/journal.ppat.0020069

42. Grenha, A.; Gomes, M. E.; Rodrigues, M.; Santo, V. E.; Mano, J. F.; Neves, N. M.; Reis, R. L. J. Biomed. Mater. Res., Part A 2010, 92A, 1265-1272. doi:10.1002/jbm.a.32466

43. McHugh, T. H.; Krochta, J. M. J. Agric. Food Chem. 1994, 42, 841-845. doi:10.1021/jf00040a001

44. Barnes, H.; Hutton, J.; Walers, K. An Introduction to Rheology; Elsevier: Amsterdam, 1989.

45. Clasen, C.; Kulicke, W.-M. Prog. Polym. Sci. 2001, 26, 1838-1919. doi:10.1016/S0079-6700(01)00024-7

46. Iglauer, S.; Wu, Y.; Shuler, P.; Tang, Y.; Goddard, W. A., III. J. Petrol. Sci. Eng. 2011, 75, 304-311. doi:10.1016/j.petrol.2010.11.025

47. Elias, H. An Introduction to Polymer Science; VCH: Weinheim, 1997.

48. Benedict, B.; Pehrsson, P. E.; Zhao, W. J. Phys. Chem. B 2005, 109, 7778-7780. doi:10.1021/jp0406161

49. Tsaih, M. L.; Chen, R. H. J. Appl. Polym. Sci. 2003, 90, 3526-3531. doi:10.1002/app.13027

50. Coleman, J. N.; Cadek, M.; Ryan, K. P.; Fonseca, A.; Nagy, J. B.; Blau, W. J.; Ferreira, M. S. Polymer 2006, 47, 8556-8561. doi:10.1016/j.polymer.2006.10.014

51.Peng, X. Y.; Sajjad, M.; Chu, J.; Yang, B. Q.; Feng, P. X. Appl. Surf. Sci. 2011, 257, 4795-4800. doi:10.1016/j.apsusc.2010.12.041

52. Feng, P. X.; Zhang, H. X.; Peng, X. Y.; Sajjad, M.; Chu, J. Rev. Sci. Instrum. 2011, 82, 043303. doi:10.1063/1.3581207

\section{License and Terms}

This is an Open Access article under the terms of the Creative Commons Attribution License

(http://creativecommons.org/licenses/by/2.0), which permits unrestricted use, distribution, and reproduction in any medium, provided the original work is properly cited.

The license is subject to the Beilstein Journal of Nanotechnology terms and conditions:

(http://www.beilstein-journals.org/bjnano)

The definitive version of this article is the electronic one which can be found at:

doi:10.3762/bjnano.3.48 